\title{
Sphingosine-1-Phosphate Receptor Antagonism Enhances Proliferation and Migration of Engrafted Neural Progenitor Cells in a Model of Viral-Induced Demyelination
}

\author{
Caroline A. Blanc, ${ }^{*}$ Jonathan J. Grist, ${ }^{\dagger}$ Hugh Rosen, ${ }^{\ddagger}$ Ilse Sears-Kraxberger, ${ }^{\S}$ Oswald Steward, ${ }^{\S}$ and Thomas E. Lane
}

\begin{abstract}
From the Department of Molecular Biology and Biochemistry* and the Departments of Anatomy and Neurobiology and Neurobiology and Behavior ${ }^{\S}$ Reeve-Irvine Research Center Irvine School of Medicine, University of California, Irvine, California; the Department of Pathology, ${ }^{\dagger}$ University of Utah School of Medicine, Salt Lake City, Utah; the Department of Chemical Physiology, ${ }^{\ddagger}$ The Scripps Research Institute, La Jolla, California
\end{abstract}

\author{
Accepted for publication \\ June 25, 2015. \\ Address correspondence to \\ Thomas E. Lane, Ph.D., \\ Department of Pathology, \\ University of Utah School of \\ Medicine, $15 \mathrm{~N}$ Medical Dr E, \\ 2600 Jones Medical Research \\ Building, Salt Lake City, \\ UT 84112. E-mail: tom.lane@ \\ path.utah.edu.
}

\begin{abstract}
The oral drug FTY720 affects sphingosine-1-phosphate (S1P) signaling on targeted cells that bear the S1P receptors S1P1, S1P3, S1P4, and S1P5. We examined the effect of FTY720 treatment on the biology of mouse neural progenitor cells (NPCs) after transplantation in a viral model of demyelination. Intracerebral infection with the neurotropic JHM strain of mouse hepatitis virus (JHMV) resulted in an acute encephalomyelitis, followed by demyelination similar in pathology to the human demyelinating disease, multiple sclerosis. We have previously reported that intraspinal transplantation of mouse NPCs into JHMV-infected animals resulted in selective colonization of demyelinated lesions, preferential differentiation into oligodendroglia accompanied by axonal preservation, and increased remyelination. Cultured NPCs expressed transcripts for S1P receptors S1P1, S1P2, S1P3, S1P4, and S1P5. FTY720 treatment of cultured NPCs resulted in increased mitogen-activated protein kinase phosphorylation and migration after exposure to the chemokine CXCL12. Administration of FTY720 to JHMV-infected mice resulted in enhanced migration and increased proliferation of transplanted NPCs after spinal cord engraftment. FTY720 treatment did not improve clinical disease, diminish neuroinflammation or the severity of demyelination, nor increase remyelination. These findings argue that FTY720 treatment selectively increases NPC proliferation and migration but does not either improve clinical outcome or enhance remyelination after transplantation into animals in which immune-mediated demyelination is initiated by the viral infection of the central nervous system. (Am J Pathol 2015, 185: 2819-2832; http://dx.doi.org/10.1016/j.ajpath.2015.06.009)
\end{abstract}

Intracranial infection with the neurotropic JHM strain of mouse hepatitis virus (JHMV) results in an acute encephalomyelitis, followed by chronic demyelination characterized by viral persistence within the central nervous system (CNS), axonal damage, and demyelination. ${ }^{1-7}$ Previous studies from our laboratory have used the JHMV model of neuroinflammation-mediated demyelination to evaluate the therapeutic benefit of mouse neural progenitor cell (NPC) engraftment on remyelination. ${ }^{8-10}$ Transplantation of mouse NPCs into the spinal cords of JHMV-infected mice results in extensive migration and colonization of areas of white matter damage and preferential differentiation into oligodendroglia. ${ }^{8-10}$ Engrafted NPCs physically engage damaged axons, and this ultimately leads to increased axonal integrity that correlates with remyelination. ${ }^{8,11}$ These findings, along with others, ${ }^{12-14}$ argue that engraftment of NPCs may provide an important unmet clinical need for treatment of human demyelinating

Supported in part by NIH grants R01 NS041249 and R01 NS074987 (T.E.L.), MH084812 (H.R.), and NS047718 (O.S.); the Hausman Family Foundation and Dawn Beattie (T.E.L.); Cure Medical and Research for Cure donations (O.S.); and private donations made directly to the laboratory (T.E.L.).

Disclosures: None declared. 
diseases, including multiple sclerosis (MS), by facilitating sustained remyelination that can restore motor function and ameliorate clinical symptoms.

After engraftment of NPCs into the spinal cords of JHMV-infected mice, transplanted cells migrate both rostral and caudal from the implantation site. ${ }^{8,9}$ The chemokine ligand CXCL12 is enriched within areas of demyelination, and transplanted NPCs express the signaling receptor CXCR4, resulting in colonization of areas of white matter damage. Blocking CXCR4 signaling on NPC transplantation impaired NPC migration, arguing for an important role for this chemokine signaling pathway in contributing to repair by mediating trafficking to sites of myelin damage. ${ }^{9}$ However, the molecular mechanisms governing positional migration of NPCs are likely complex and consist of additional soluble factors that affect the ability of NPCs to effectively congregate within areas of white matter pathology.

Among potential molecules that may influence migration is the lysophospholipid sphingosine-1-phosphate (S1P) that is well documented in controlling proliferation and migration of numerous cell types. ${ }^{15-18}$ Although the importance of S1P signaling in controlling lymphocyte homing and egress from lymphatic tissues is well documented, ${ }^{19-21}$ increasing evidence indicates a functional role within the CNS as glia and neurons express different combinations of specific signaling receptors S1P1, S1P2, S1P3, S1P4, and S1P5. ${ }^{22,23}$ Activation of these receptors yields different effects on migration and survival of astrocytes, microglia, and oligodendrocytes. ${ }^{24-26}$ In addition, NPCs express S1P receptors, and signaling has previously been reported to influence in vitro differentiation. ${ }^{27}$ Moreover, Kimura et $\mathrm{al}^{28}$ demonstrated an important role for S1P signaling in controlling migration of transplanted NPCs to an injury site in a model of spinal cord injury.

We examined the functional role of S1P signaling after NPC transplantation into the spinal cords of JHMV-infected mice. FTY720 is a U.S. Food and Drug Administration-approved oral drug for treatment of patients with relapsing MS. ${ }^{22,23,29-31}$ FTY720 exerts immunomodulatory effects that reduce acute relapses, new lesion formation, and disability progression and brain volume loss in MS patients. ${ }^{32}$ The mechanism(s) behind FTY720 functions are not yet defined; however, the phosphorylated active form of FTY720 (FTY720P) is an S1P receptor modulator that inhibits egress of lymphocytes from lymph nodes. FTY720 is a functional antagonist of S1P1 on lymphocytes, ${ }^{20}$ yet also can act as a nonselective agonist of S1P1, S1P3, S1P4, and S1P5. ${ }^{33}$ Therefore, the available evidence suggests that cellular source and receptor expression profile are critical in terms of how FTY720 affects S1P signaling, and likely lead to a dampening of autoreactive $T$ cells specific for myelin antigens infiltrating into the CNS. More important, FTY720, because of its lipophilic nature, penetrates the blood-brain barrier and readily enters the CNS parenchyma. Furthermore, FTY720P is detected in situ, suggesting that it may influence the biology of resident cells of the CNS. Our findings reveal that treatment of cultured NPCs with FTY720P led to an active signaling response, as determined by phosphorylation of mitogenactivated protein (MAP) kinase, yet did not influence lineage fate commitment. FTY720 treatment of JHMV-infected mice, transplanted with NPCs, demonstrated enhanced migration associated with increased numbers of NPCs compared with vehicle-treated control animals. FTY720 treatment did not affect the accumulation of $\mathrm{T}$ cells or macrophages within the CNS. Finally, after treatment in animals in which demyelination is established, FTY720 did not augment the effects of NPCs on influencing remyelination, indicating a selective effect on migration/proliferation on spinal cord engraftment into JHMV-infected mice.

\section{Materials and Methods}

\section{Mice and Virus}

Age-matched (5 to 7 weeks) S1P1 enhanced green fluorescent protein (eGFP) knock-in mice (C57BL/6 background $)^{34}$ and C57BL/6 mice were anesthetized with an i.p. injection of $150 \mu \mathrm{L}$ of a mixture of ketamine (Western Medical Supply, Arcadia, CA) and xylazine (Phoenix Pharmaceutical, Saint Joseph, MO) in Hanks' balanced salt solution. Mice were injected intracranially with 150 plaqueforming units of JHMV (strain V2.2-1) suspended in $30 \mu \mathrm{L}$ saline. ${ }^{9}$ Clinical severity was assessed by blinded investigators (T.E.L. and C.A.B.) using a previously described four-point scoring scale. ${ }^{35}$ FTY720 (2-amino-2-[2-(4octylphenyl) ethyl]-1,3-propanediol, hydrochloride) and FTY720P (2-amino-2 [2-(4-octylphenyl) ethyl]-1,3propanediol, mono dihydrogen phosphate ester) were purchased from Cayman Chemical Co (Ann Arbor, MI). FTY720 or the vehicle was administered by daily i.p. injections of $100 \mu \mathrm{L}$, starting at day 13 postinfection (p.i.). Experiments for all animal studies were reviewed and approved by the University of Utah (Salt Lake City) and the University of California (Irvine) Institutional Animal Care and Use Committees.

\section{NPC Isolation and Culture}

Neurosphere cultures were prepared from brains of perinatal S1P1 eGFP knock-in mice, as previously described. ${ }^{8,36}$ Briefly, dissected striata were razor minced and triturated in $0.05 \%$ trypsin for 10 minutes, followed by anti-trypsin to inactivate the digestion. Single cells were resuspended in Dulbecco's modified Eagle's medium:F12 (Invitrogen, Carlsbad, CA) supplemented with B27 (Invitrogen), insulintransferrin-selenium-X (Invitrogen), penicillin-streptomycin (Invitrogen), 40 ng/mL T3 (T67407; Sigma, St. Louis, $\mathrm{MO}$ ), and $20 \mathrm{ng} / \mathrm{mL}$ human recombinant epidermal growth factor (E9644; Sigma). Cells were cultured for 6 days with replacement of media every other day, at which point 
mature neurospheres were isolated and GFP expression was visualized by fluorescence microscopy.

\section{PCR}

Total RNA was extracted from neurospheres, DNase treated, and purified via phenol-chloroform extraction. cDNA was synthesized with a reverse transcription kit superscript VILO (Invitrogen), according to the manufacturer's instructions. The following primers were used to identify S1P1-S1P5 mRNA expression: S1P1, 5'-TTTCCATCGCCATCCTCTAC-3' (forward) and 5'-GCAGGCAATGAAGACACTCA-3' (reverse); S1P2, 5'-TCTCAGGGCATGTCACTCTG-3' (forward) and 5'-CAGCTTTTGTCACTGCCGTA- $3^{\prime}$ (reverse); S1P3, 5'-GTGTGTTCATTGCCTGTTGG-3' (forward) and $5^{\prime}$-TTGACTAGACAGCCGCACAC- $3^{\prime}$ (reverse); S1P4, 5'-GGCTACTGGCAGCTATCCTG-3' (forward) and $5^{\prime}$-AAGGCCACCAAGATCATCAG-3' (reverse); and S1P5, 5'-GATCCCTTCCTGGGTCTAGC$3^{\prime}$ (forward) and 5'-TAGAGCTGCGATCCAAGGTT-3' (reverse). Primers were purchased from Invitrogen. Sequencing of PCR amplicons confirmed primer specificity.

\section{Western Blot Analysis}

NPCs were plated on Matrigel-coated 6-well plates and treated with either $100 \mathrm{nmol} / \mathrm{L}$ FTY720 phosphate or vehicle for 5 minutes, 30 minutes, 1 hour, 2 hours, and 4 hours. The cells were then lysed using radioimmunoprecipitation assay buffer [50 mmol/L Tris-HCL (pH 7.4), $175 \mathrm{mmol} / \mathrm{L} \mathrm{NaCl}, 5 \mathrm{mmol} / \mathrm{L}$ EDTA, $1 \%$ NP-40, $0.1 \%$ SDS, and $0.5 \%$ deoxycholic acid] supplemented in protease and phosphatase inhibitors (Roche). P44/42 MAP kinase (1:2000; Cell Signaling, Danvers, MA) and phosphorylated p44/42 MAP kinase (1:15,000; Cell Signaling) were detected by Western blot analysis using horseradish peroxidase-conjugated secondary antibodies (1:25,000; Jackson ImmunoResearch Laboratory, West Grove, PA) and exposed to Supersignal West-Femto chemiluminescent reagent (Pierce, Rockford, IL).

\section{NPC Differentiation}

To assess differentiation potential, NPCs expressing $\mathrm{GFP}^{8,9,11,37}$ were grown on Matrigel-coated chamber slides with epidermal growth factor for 24 hours, at which point growth factor was removed and NPCs were allowed to differentiate for up to 7 days. ${ }^{8}$ Cells were treated daily with $100 \mathrm{nmol} / \mathrm{L}$ FTY720P or vehicle subsequently fixed in $4 \%$ paraformaldehyde for 20 minutes at room temperature. Immunofluorescence was performed using established protocols: rabbit-anti-mouse Olig 2 (1:200; Millipore, Darmstadt, Germany), rabbit-anti-mouse glial fibrillary acidic protein (1:1000; Invitrogen), mouse-anti-mouse Map2 (1:750; Sigma), Alexa-594 anti-rabbit (1:500; Invitrogen), and anti-mouse (1:1000; Invitrogen) were used as secondary antibodies. Samples were then washed in phosphate-buffered saline (PBS), and coverslip was mounted with DAPI Vectashield Mounting Medium (Vector Laboratories, Burlingame, CA). The percentage of immunopositive cells for each stain was determined by dividing the total number of immunopositive cells by the total number of DAPI-positive cells.

\section{NPC Transplantation}

Transplantation was performed on day 14 p.i. with JHMV, at which point infected mice have established demyelination. ${ }^{8,9,11}$ Mice were anesthetized with an i.p. injection of $150 \mu \mathrm{L}$ of a mixture of ketamine (Western Medical Supply, Arcadia, CA) and xylazine (Phoenix Pharmaceutical, Saint Joseph, MO) in Hanks' balanced salt solution, a laminectomy was performed at T9, and $2.5 \times 10^{5} \mathrm{NPC}$ s resuspended in 2.5 $\mu \mathrm{L}$ solution were injected into the spinal cord using a $10-\mu \mathrm{L}$ Hamilton syringe, as previously described. ${ }^{8,38-40}$ Recipient mice also received daily i.p. injections of $3 \mathrm{mg} / \mathrm{kg}$ FTY720 starting at day 13 p.i., whereas a control group received vehicle starting at day 13 p.i.

\section{NPC Chemotaxis}

In vitro chemotaxis assays were performed using a NeuroProbe ChemoTx system, according to the manufacturer's protocol. Briefly, GFP-NPCs treated with $100 \mathrm{nmol} / \mathrm{L}, 10 \mathrm{nmol} / \mathrm{L}$, and 1 $\mu \mathrm{mol} / \mathrm{L}$ FTY720P or vehicle control were allowed to migrate in response to recombinant mouse CXCL12 (Peprotech, Rocky Hill, NJ). Migration after 16 hours of culture was assessed by a fluorescent microplate reader (Synergy H1; BioTek, Winooski, VT), according to manufacturer's specifications.

\section{Histology}

Spinal cords were isolated at defined time points and fixed overnight with $4 \%$ paraformaldehyde at $4^{\circ} \mathrm{C}$. Individual spinal cords were divided into sections, and twelve coronal sections ( $1 \mathrm{~mm}$ thick) were cryoprotected in $20 \%$ sucrose and embedded in OCT (VWR, Radnor, PA). Coronal sections $(8 \mu \mathrm{m}$ thick) were cut, and sections were stained with luxol fast blue. Areas of total white matter and demyelinated white matter were determined with ImageJ software version 1.48 (NIH, Bethesda, MD; http://imagej.nih.gov/ij). ${ }^{41}$ Demyelination was scored as a percentage of total demyelination along the entire length of the spinal cord. The total numbers of GFP-positive cells were determined in each of the twelve spinal cord sections surrounding the transplant site by counting GFP-positive cells colocalized with DAPIpositive nuclei. Determination of both the severity of demyelination and numbers of GFP-positive cells was performed blinded (T.E.L. and C.A.B.).

\section{Electron Microscopy}

Mice were perfused with $0.1 \mathrm{~mol} / \mathrm{L}$ cacodylate buffer containing $2 \%$ paraformaldehyde $/ 2 \%$ glutaraldehyde, and spinal 
cords were isolated, and then embedded in Epon (Danbury, CT) epoxy resin. Serial ultrathin sections were stained with uranyl acetate-lead citrate and analyzed as previously described. Images at $\times 1200$ magnification were analyzed for $g$-ratio using ImageJ software. ${ }^{42}$ A minimum of 150 axons were analyzed per mouse, and the $g$-ratio was calculated by dividing the axon diameter by the total fiber diameter.

\section{Immunofluorescence}

For immunophenotyping of glial cells, fixed spinal cord sections were incubated in 10\% normal goat serum (Jackson ImmunoResearch, West Grove, PA) and 1\% bovine serum albumin for 1 hour at room temperature. This was followed by an overnight incubation at $4^{\circ} \mathrm{C}$ with the following primary antibodies in $1 \%$ bovine serum albumin: rabbit anti-mouse glutathione $S$-transferase (GST)- $\pi$ (1:1000; MBL, International Corporation, Woburn MA), rabbit-anti-mouse glial fibrillary acidic protein (GFAP; 1:1000; Invitrogen), and rabbit-anti-mouse Ki-67 (1:300; Abcam, Cambridge, MA). Sections were then washed in PBS and incubated for 1 hour at room temperature with Alexa fluorescent-conjugated secondary antibodies (goat-anti-rabbit Alexa 594 or goat-anti-mouse Alexa 594; 1:1000 in PBS; Invitrogen). Next, sections were washed in PBS and coverslip mounted using DAPI Vectashield Mounting Medium (Vector Laboratories). The percentage of immunopositive cells for each stain was determined by dividing the total number of immunopositive cells by the total number of DAPI-positive cells.

\section{Cell Isolation and Flow Cytometry}

Brain, spinal cords, and blood were isolated at day 21 or 28 p.i. from infected mice treated with $3 \mathrm{mg} / \mathrm{kg}$ FTY 720 or vehicle, starting at day 13 p.i. and transplanted with GFPlabeled NPCs. By using previously described protocols, ${ }^{41}$ tissues were then homogenized and immunophenotyped by flow cytometry using the following antibodies: rat-antimouse CD4-allophycocyanin (1:50; Biolegend, San Diego, CA), rat-anti-mouse CD8-allophycocyanin (1:50; Biolegend), S510 to S518 tetramer-phosphatidylethanolamine (1:300; $\mathrm{NIH}$ ), and M133 to M147 tetramer-phosphatidylethanolamine (1:150; NIH). Blood was collected by cardiac heart puncture, and cells were stained with rat-anti-mouse CD4allophycocyanin and CD8-phosphatidylethanolamine after red blood cell lysis. Samples were analyzed using a BD-Fortessa X-20 Flow Cytometer (BD Biosciences, Franklin Lakes, NJ).

\section{Results}

\section{FTY720 Treatment Activates Cultured NPCs}

FTY720 functions as both an antagonist and agonist for members of the S1P receptor family whose natural ligand

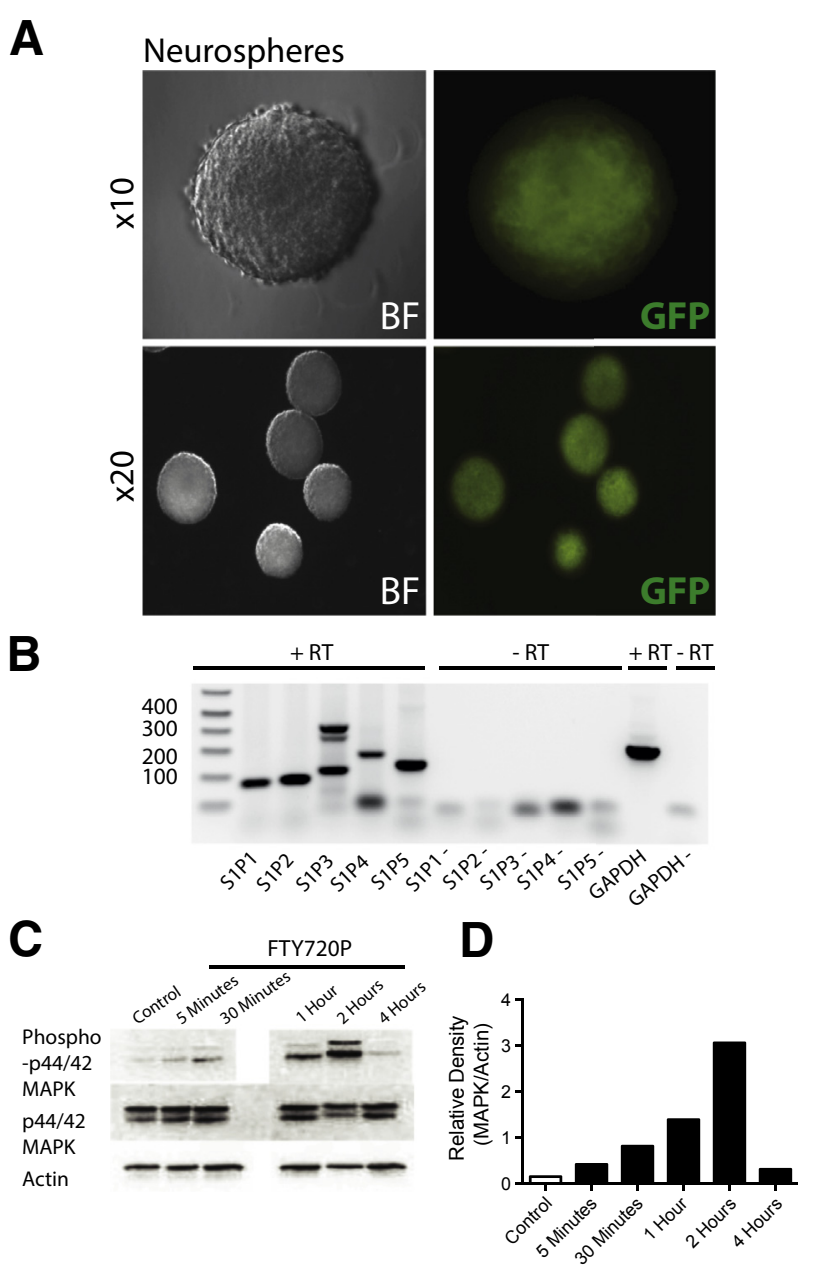

Figure 1 FTY720 treatment activates cultured neural progenitor cells (NPCs). Neurospheres were isolated from the subventricular zone of sphingosine-1-phosphate receptor 1 (S1P1) enhanced green fluorescent protein (eGFP) neonatal pups. A: Representative immunofluorescence images confirm that neurospheres express S1P1, as evidenced by GFP expression. B: Analysis of S1P receptor expression by NPCs at the mRNA level demonstrates expression of transcripts specific for S1P1 to S1P5; the sequence of amplicons confirmed primer specificity. C: Western blot analysis of cultured NPCs treated with either vehicle or $100 \mathrm{nmol} / \mathrm{L}$ phosphorylated active form of FTY720 (FTY720P) reveals increased phosphorylation over time. D: Quantitative analysis of Western blot data confirms increased phosphorylation of mitogen-activated protein kinase (MAPK). Analyses of band intensity on films are presented as the relative ratio of phosphorylated MAPK/actin. BF, brightfield microscopy; GAPDH, glyceraldehyde-3-phosphate dehydrogenase.

is S1P. Previous studies have demonstrated that FTY720 preferentially binds S1P1, S1P3, S1P4, and S1P5 receptors, including lower affinity for S1P4, but does not bind to S1P2. ${ }^{19}$ We tested whether mouse NPCs expressed S1P receptors and if FTY720 treatment affected defined responses. Neurospheres were isolated from the subventricular zone of day 1 old eGFP-S1P1 knock-in mice, ${ }^{8,36}$ and immunofluorescence confirmed that NPCs express S1P1, as evidenced by GFP expression (Figure 1A). Subsequent analysis of additional S1P receptor expression by RT-PCR demonstrated expression of transcripts for all five defined 

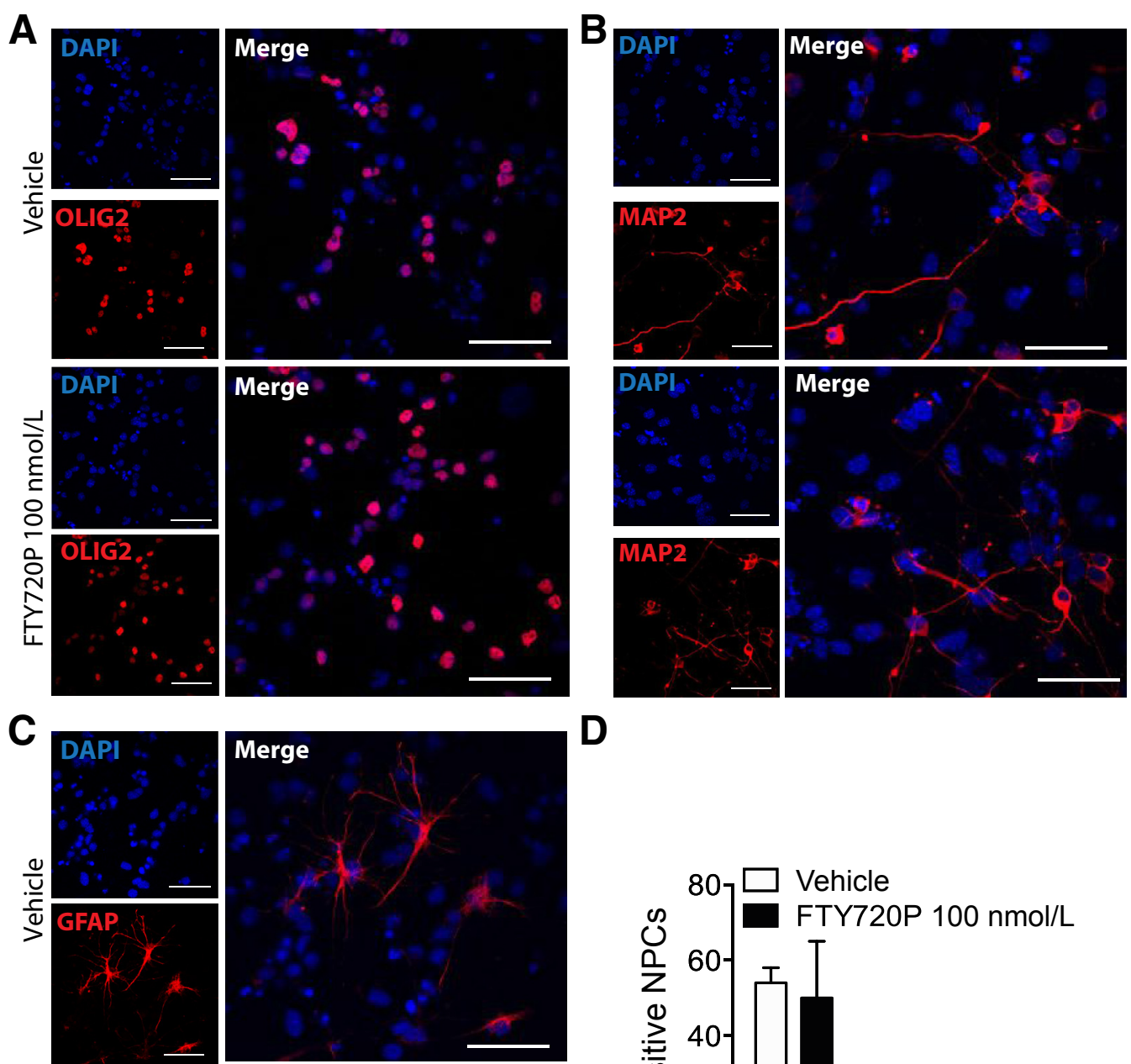

D
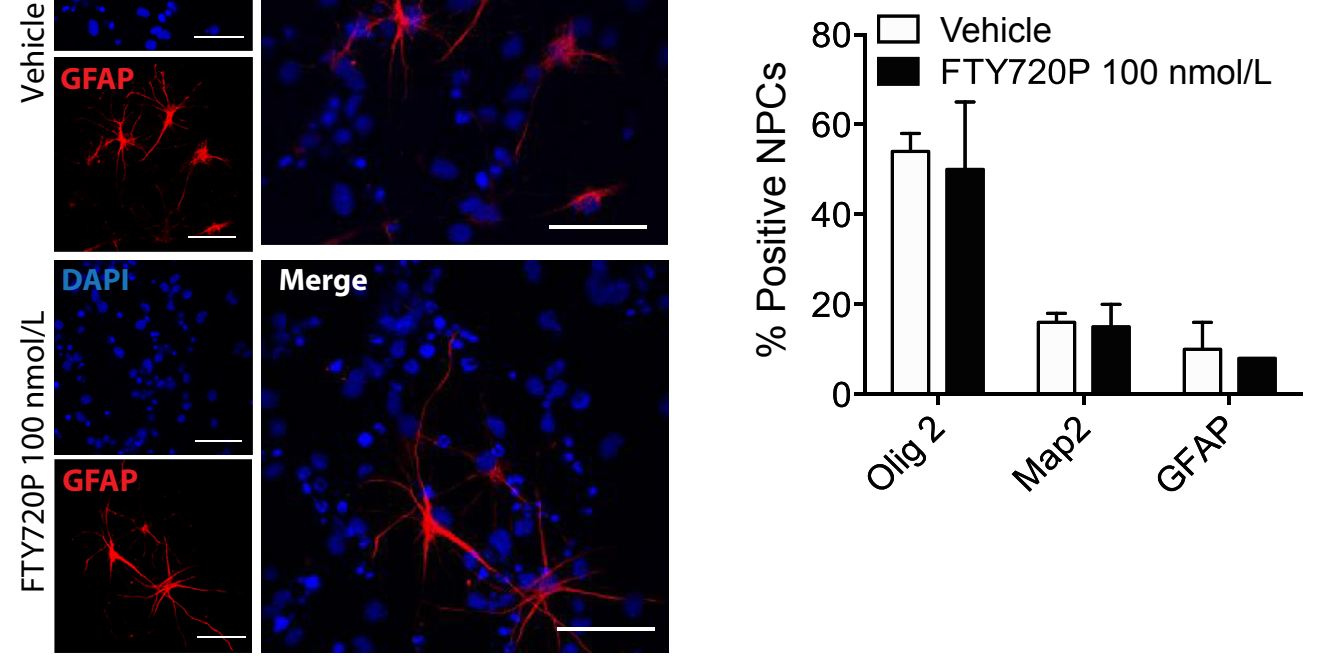

Figure 2 FTY720 does not affect neural progenitor cell (NPC) differentiation. Exposure of cultured NPCs to daily 100 nmol/L phosphorylated active form of FTY720 (FTY720P) for 5 days does not influence lineage fate commitment to either oligodendroglia (0lig2; A), neurons [mitogen-activated protein (Map) 2; B], and astrocytes [glial fibrillary acidic protein (GFAP); C] compared with vehicle-control-treated cultures. D: Quantification of immunocytochemical staining for defined cell lineages indicates similar frequencies of Olig2-, MAP2-, and GFAP-positive cells after treatment of cultured NPCs with either vehicle or FTY720P. Data were presented as means \pm SEM (D). $n=3$ independent experiments (D).

S1P receptors (Figure 1B). Previous studies have demonstrated that FTY720 treatment activates several intracellular signaling cascades, including phosphorylation of MAP kinase. ${ }^{43,44}$ Treatment of cultured NPCs with the activated FTY720P $(100 \mathrm{nmol} / \mathrm{L})$ resulted in phosphorylation of MAP kinase in a time-dependent manner, indicating receptor binding and activation (Figure 1, C and D). These findings support earlier studies ${ }^{15}$ demonstrating that NPCs express S1P receptors and FTY720 treatment initiates activation of intracellular signaling pathways.

\section{FTY720 Does Not Affect NPC Differentiation}

We next tested whether exposure of cultured NPCs to FTY720 influenced lineage fate commitment. Under defined conditions, cultured NPCs will preferentially differentiate into oligodendroglia, although astrocytes and neurons are 
A

Vehicle d21 p.t

\begin{tabular}{llll|llll}
1 & 2 & 3 & 4 & 5 & 6 & 7 & 8
\end{tabular}

Rostral $\quad$ Caudal FTY720 $3 \mathrm{mg} / \mathrm{kg}$ d21 p.t

Transplant Site DAPI GFP

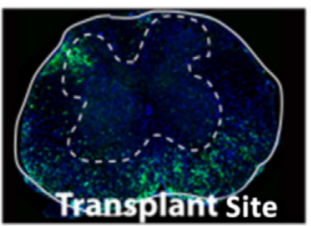

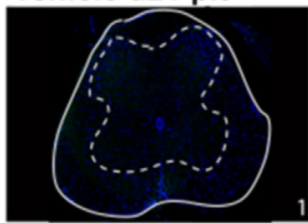
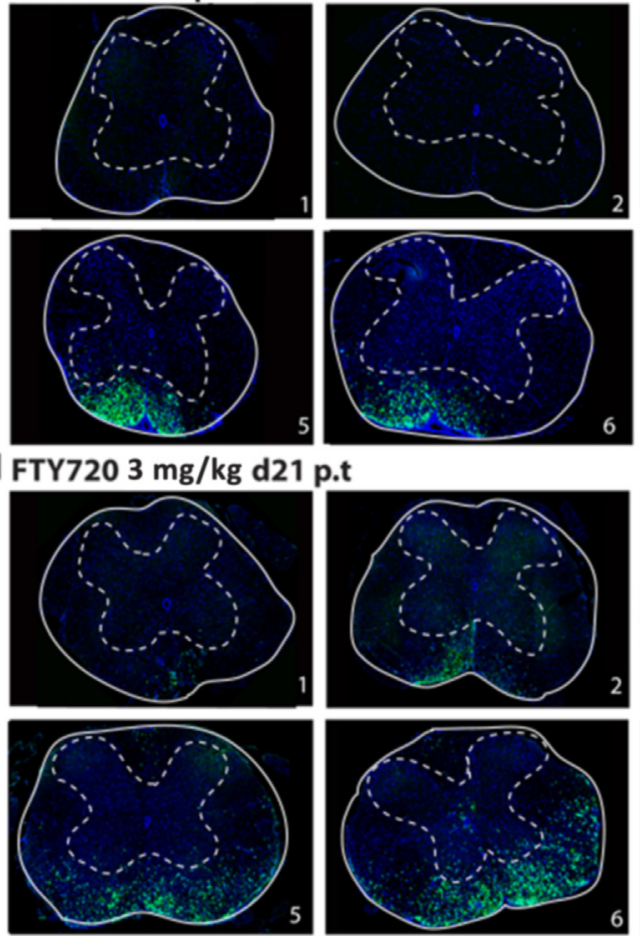
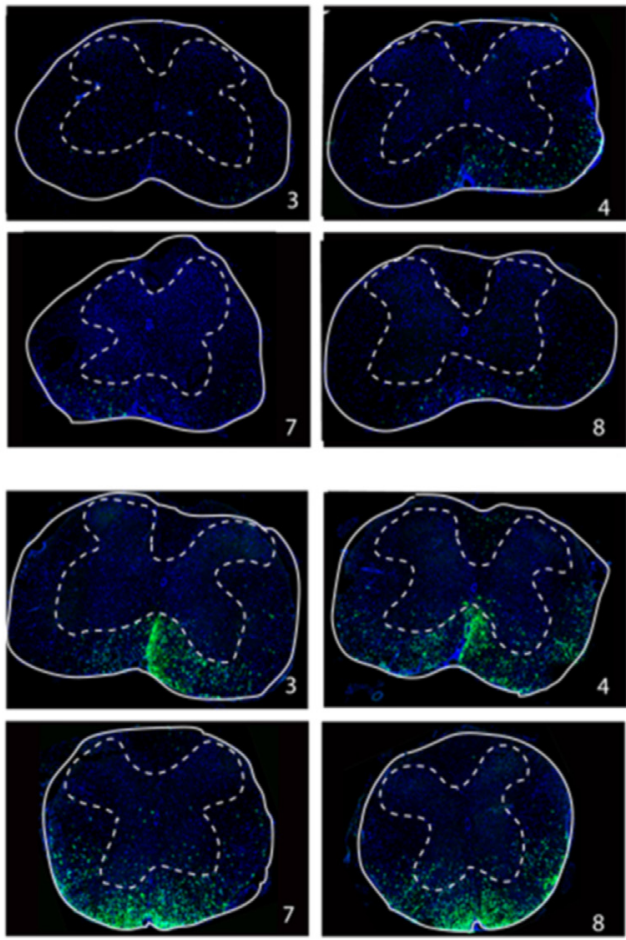

B

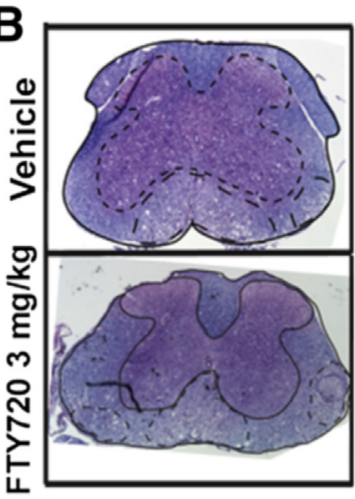

D

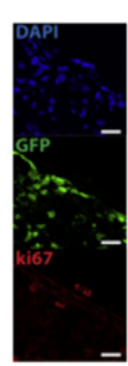

Vehicle

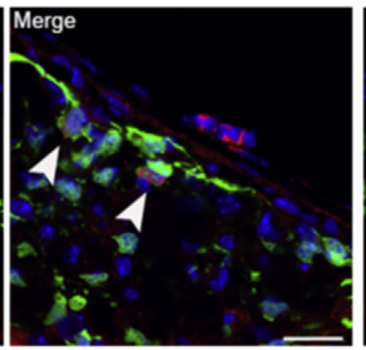

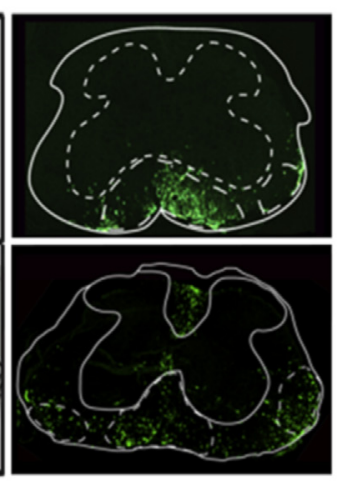

FTY7203 mg/kg

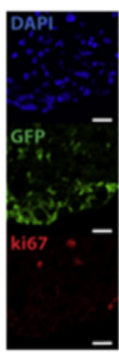

\section{作}

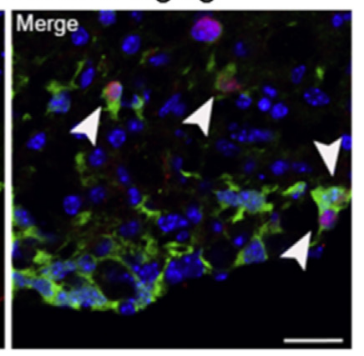

C

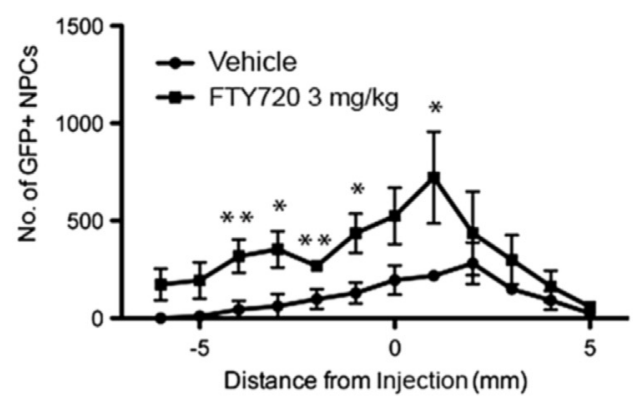

E

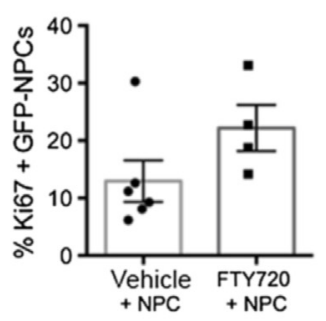

Figure 3 FTY720 treatment enhances migration of engrafted green fluorescent protein (GFP)-neural progenitor cells (NPCs). JHMV-infected mice were treated with FTY720 (3 mg/kg daily via i.p. injection) or vehicle control beginning at day 13 postinfection (p.i.). GFP-expressing NPCs were transplanted into the spinal cords at day 14 p.i., and migration of transplanted cells rostral and caudal to the implantation site was assessed 3 weeks posttransplant (p.t.). A: Transplanted GFP-NPCs migrate both rostral and caudal from the implantation site in both control and FTY720-treated mice. Images represent spinal cord sections rostral (1 to 4 ) and caudal (5 to 8) from the transplantation site. B: Transplanted GFP-NPCs congregate within areas of demyelination located in the anterior and lateral funiculus in both FTY720-treated mice and vehicle control. C: Quantification of GFP-NPC cell numbers at defined spinal cord sections rostral and caudal to the implantation site in vehicle control and FTY720-treated animals. D: Representative images depicting Ki-67 staining by transplanted GFP-NPCs in vehicle control and FTY720-treated mice. Arrowheads represent Ki-67 $7^{+}$transplanted GFP-NPCs. E: Quantification of GFP-NPCs expressing Ki-67. Data are presented as means \pm SEM (C and E). $n=2$ or more independent experiments with $n=4$ or more mice per group $(\mathbf{C}$ and $\mathbf{E})$. ${ }^{*} P<0.05$, $* * P<0.01$. 

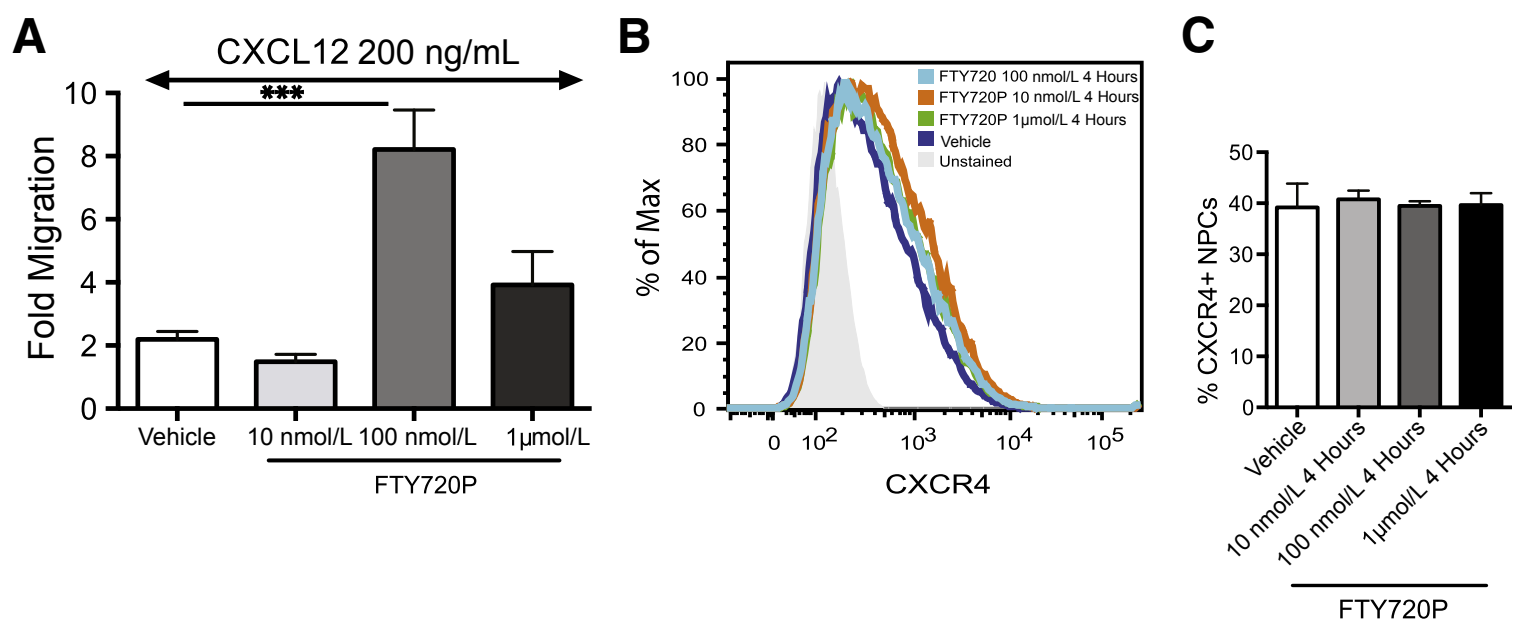

Figure 4 FTY720 does not affect CXCR4 expression by neural progenitor cells (NPCs). A: Cultured NPCs were treated with increasing concentrations of phosphorylated active form of FTY720 (FTY720P; $10 \mathrm{nmol} / \mathrm{L}, 100 \mathrm{nmol} / \mathrm{L}$, and $1 \mu \mathrm{mol} / \mathrm{L}$ ), and migration in response to $200 \mathrm{ng} / \mathrm{mL}$ recombinant mouse CXCL12 was determined after 16 hours. Exposure to FTY720P results in a dose-dependent migration response. B: Representative flow analysis reveals that FTY720 treatment does not affect surface expression of CXCR4 by cultured NPCs at a defined concentration. C: This is confirmed by quantification of mean fluorescence intensity of CXCR4 expression of cultured cells under experimental conditions. Data are given as means \pm SEM (A and C). $n=2$ independent experiments (A); $n=3$ independent experiments $(\mathbf{C}) .{ }^{* * *} P<0.001$. Max, maximum.

also present. ${ }^{8,9}$ Exposure of NPCs to $100 \mathrm{nmol} / \mathrm{L}$ FTY720P did not influence differentiation because we detected similar frequencies of oligodendroglia (Olig2 positive), astrocytes (GFAP), and neurons (Map2) when compared with vehiclecontrol-treated cultures (Figure 2, A-D). Therefore, S1P receptor antagonism does not affect NPC differentiation.

\section{FTY720 Treatment Enhances Migration of Engrafted GFP-NPCs}

To test if FTY720 affects migration of engrafted NPCs, JHMV and GFP-expressing NPCs (GFP-NPCs) were transplanted into the spinal cord at day 14 p.i., ${ }^{8,11,37,39}$ and FTY720 treatment (3 $\mathrm{mg} / \mathrm{kg}$, daily, via i.p. injection) was initiated at day 13 p.i. Control groups consisted of JHMV-infected mice transplanted with GFP-NPCs treated with vehicle only. Mice were sacrificed at 3 weeks posttransplant, and GFP-NPC distribution was assessed histologically in spinal cord cross sections. In both FTY720 and vehicle-treated control mice, GFP-NPCs were distributed rostral and caudal from the implantation site and colonized areas of demyelination within the ventral funiculus and lateral white matter columns (Figure 3, A and B). Quantification of GFP-NPCs in defined spinal cord sections rostral and caudal to the implantation site indicated a significant $(P<0.05)$ increase in numbers of GFP-NPCs in FTY720-treated animals when compared with vehicle-treated mice (Figure 3C). Immunostaining for $\mathrm{Ki}-67$ revealed increased numbers of Ki-67-positive GFP-NPCs throughout the spinal cord in FTY720-treated mice, consistent with increased proliferation (Figure 3, D and E).

These findings suggest a role in S1P receptor antagonism in controlling proliferation and/or migration of NPCs engrafted into the spinal cord. We have previously shown that CXCL12 is critical in controlling the positional migration of engrafted
NPCs by signaling through CXCR4 expressed on the surface of NPCs. ${ }^{9}$ Furthermore, Kimura et a ${ }^{45}$ have reported that FTY720 treatment promotes migration of human $\mathrm{CD} 34^{+}$hematopoietic progenitor cells by enhancing CXCR4 function. Cultured NPCs were treated with increasing concentrations of FTY720P (10 $\mathrm{nmol} / \mathrm{L}, 100 \mathrm{nmol} / \mathrm{L}$, and $1 \mu \mathrm{mol} / \mathrm{L}$ ), and the in vitro migration in response to $200 \mathrm{ng} / \mathrm{mL}$ recombinant mouse CXCL12 resulted in a dose-dependent migration response (Figure 4A). Flow analysis revealed that FTY720 treatment did not affect surface expression of CXCR4 at any concentration tested (Figure 4, B and C). Therefore, administration of FTY720 enhances migration of NPCs potentially by enhancing CXCR4 function, consistent with earlier studies. ${ }^{45}$

\section{FTY720 Treatment of NPC-Transplanted Mice Does Not Affect NPC Differentiation or Demyelination}

FTY720 did not affect clinical disease in JHMV-infected mice, regardless if transplanted with GFP-NPCs or treated with vehicle (data not shown). We next examined if FTY720 treatment influenced the ability of engrafted NPCs to differentiate into oligodendroglia, because our previous studies have shown that most transplanted cells preferentially differentiate into these cells. ${ }^{8,9}$ By 14 days posttransplant, FTY720 did not affect lineage fate commitment of NPCs because similar frequencies of GST- $\pi$-positive cells (a marker for mature myelin-producing oligodendrocytes) were observed in FTY720 versus vehicle-treated mice (Figure 5, A and B). The severity of spinal cord demyelination in transplanted mice treated with FTY720 was examined by staining serial coronal sections rostral and caudal to the implantation site with luxol fast blue and quantifying the percentage of white matter damage. ${ }^{41,42}$ By day 14 posttransplant, the severity of demyelination was similar in transplanted mice treated with 

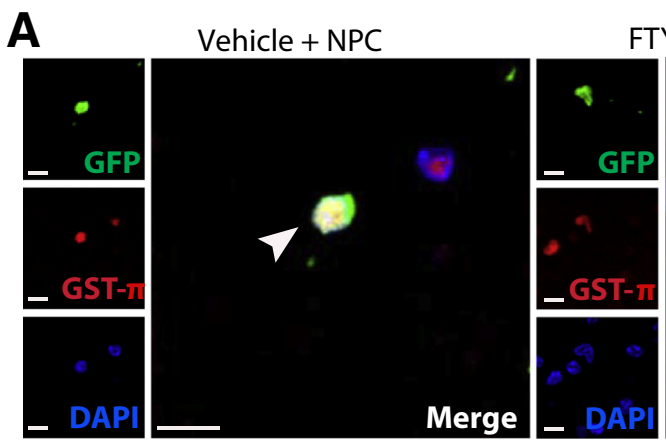

TY720 $3 \mathrm{mg} / \mathrm{kg}+\mathrm{NPC}$

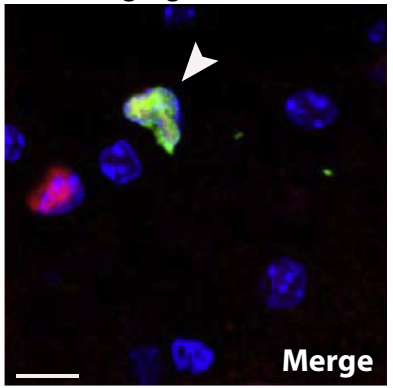

C

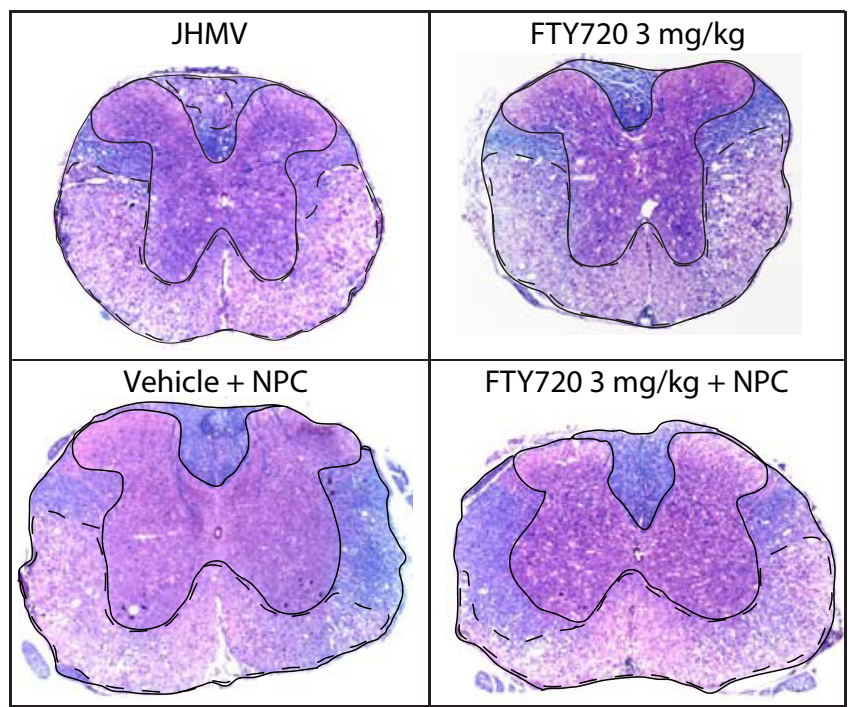

B

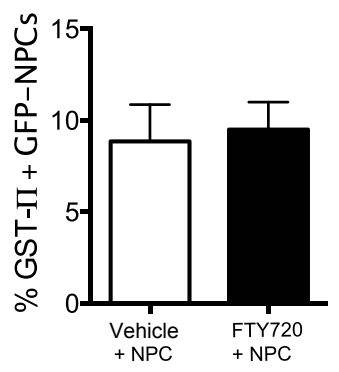

D

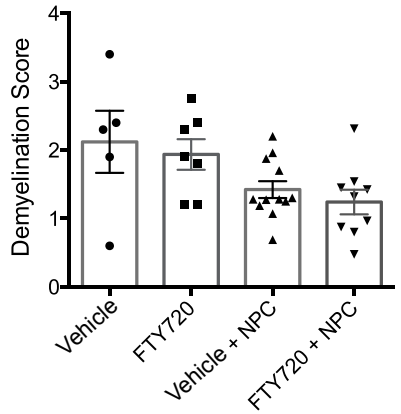

Figure 5 FTY720 does not decrease the severity of demyelination. Mice were infected with 150 plaque-forming units of JHMV and $3 \mathrm{mg} / \mathrm{kg}$ FTY720 or control vehicle treatment initiated at day 13 postinfection (p.i.) and transplanted with green fluorescent protein (GFP)-neural progenitor cells (NPCs) at day 14 p.i. In addition, JHMV-infected mice treated with FTY720 or vehicle alone served as an additional control. A: Representative glutathione $S$-transferase (GST)- $\pi$ immunofluorescence staining of spinal cords isolated at day 14 posttransplant (p.t.) from JHMV-infected mice engrafted with GFP-NPCS at day 14 p.i. and treated with either FTY720 or control at day 13 p.i. Arrowheads represent GST- $\pi$-positive transplanted GFP-NPCs. B: Similar frequencies of GFP-positive mature oligodendrocytes in GFP-NPC-transplanted mice treated with either FTY720 or vehicle. Twelve spinal cord sections per mouse were counted to determine the frequency of transplanted GFP-NPCs that differentiated into GST- $\pi-$ positive cells. C: Representative luxol fast blue-stained spinal cord sections from NPC-transplanted mice treated with either FTY720 or control vehicle, or nontransplanted mice treated with FTY720 or control vehicle at day 14 p.t. D: Quantification of demyelination indicates no differences in the severity of white matter damage in experimental groups of mice at day 14 p.t. Data are presented as means \pm SEM (B and $\mathbf{D}) . n=2$ independent experiments with $n=4$ or more mice per experimental group (B); $n=2$ independent experiments with $n=5$ or more mice per experimental group (D). Scale bar $=50 \mu \mathrm{m}(\mathbf{A})$.

FTY720 when compared with control animals (Figure 5, C and D). Electron microscopic analysis of spinal cords from experimental mice was performed to better assess whether FTY720 treatment of mice promoted remyelination. Determination of the $g$-ratio, the ratio of the inner axonal diameter/ the total outer fiber diameter, is an established structural index of remyelination, with lower ratios indicating more extensive remyelination. ${ }^{42}$ Regions of spinal cord ventral and lateral white matter tracts of JHMV-infected mice, transplanted with GFP-NPCs and treated with FTY720 or vehicle, and JHMVinfected mice treated with vehicle or FTY720 alone were analyzed (Figure 6A).

We first determined whether FTY720 treatment alone increased remyelination in JHMV-infected mice. Our findings indicate that, although there was an overall trend toward remyelination after FTY720 treatment compared with control mice, this did not reach significance (Figure 6, B, C, and F). Increased remyelination was observed in JHMV-infected mice that were transplanted with GFP-NPCs compared with vehicle treatment alone (Figure 6, B, D, and F). However, FTY720 did not result in a significant increase in remyelination in GFPNPC-treated animals compared with transplanted animals treated with vehicle alone (Figure 6, B, E, and F). Therefore, these findings argue that FTY720 treatment does not enhance remyelination in JHMV-infected mice regardless if transplanted with GFP-NPCs.

Treatment with FTY720 Does Not Affect Neuroinflammation in JHMV-Infected Mice

We have previously determined that FTY720 treatment of JHMV-infected mice during acute disease results in 

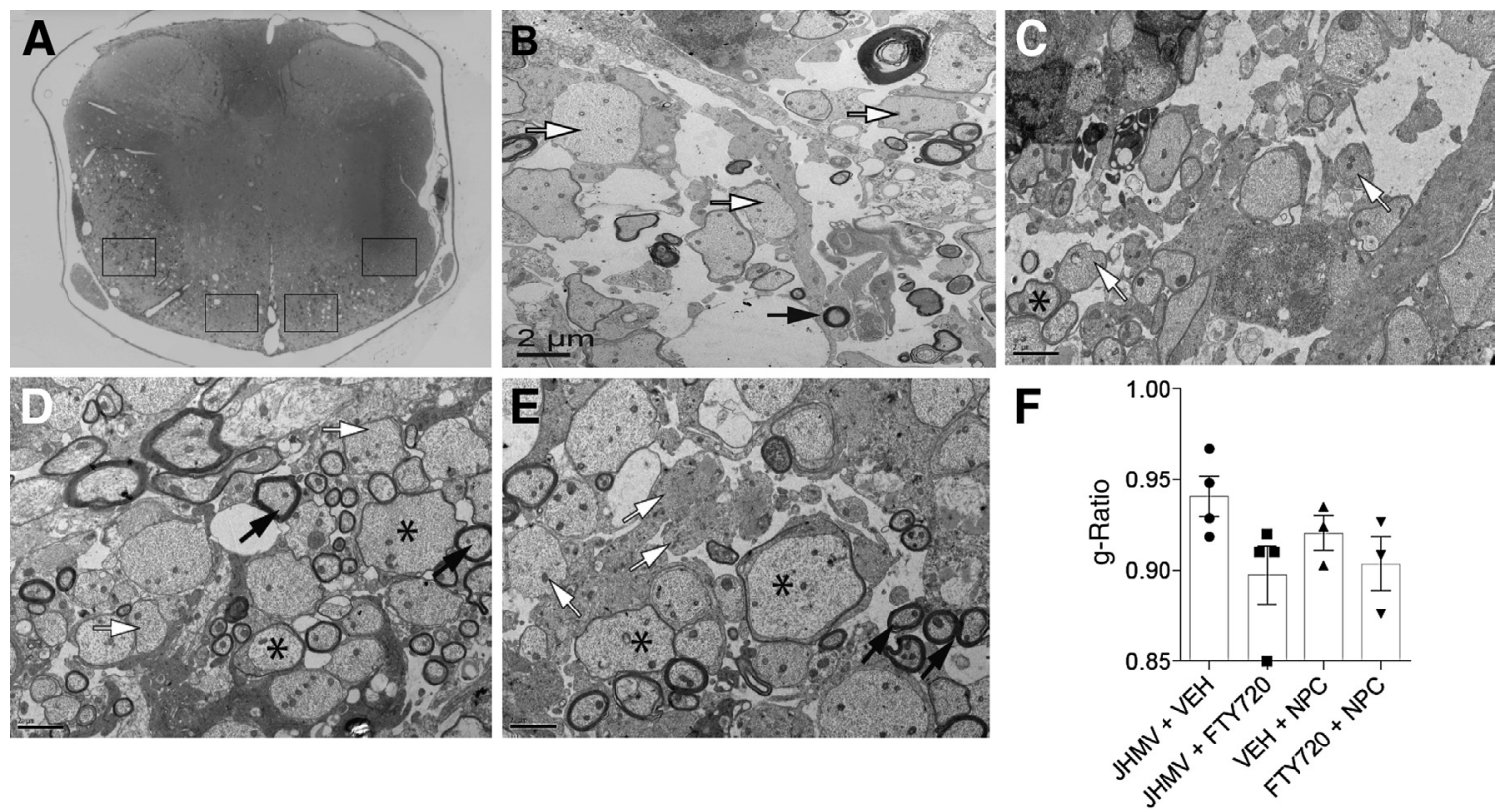

Figure 6 FTY720 treatment does not promote remyelination. A: Representative transverse spinal cord section; boxed areas indicate the regions in which demyelinated and remyelinated axons were determined. Representative electron microscopic (EM) images of spinal cords of JHMV-infected mice treated with vehicle (VEH) alone (B), FTY720 (C), green fluorescent protein (GFP)-neural progenitor cells (NPCs) and vehicle (D), and GFP-NPCs and FTY720 (E). Black arrows indicate myelinated axons; white arrows, demyelinated axons; asterisks, remyelinated axons. F: Calculation of $g$-ratio, as a measurement of axonal remyelination, shows no significant differences between experimental mice. Data are presented as means $\pm \operatorname{SEM}(\mathbf{F})$. $n=3$ per group with $n=150$ or more axons per mouse analyzed (F). Original magnification, $\times 1200(\mathbf{B}-\mathbf{E})$.

increased mortality and limited infiltration of $\mathrm{T}$ cells into the CNS, which correlated with impaired ability to control viral replication within the CNS. ${ }^{41}$ We next examined whether FTY720 treatment affected T-cell infiltration into the CNS of mice either infected with JHMV or infected and transplanted with GFP-NPCs. Mice were infected intracranially with JHMV, and mice received daily i.p. injections of FTY720 beginning at day 13 p.i. Flow analysis of T-cell infiltration into the spinal cords of infected mice isolated at day 28 p.i. indicated no differences in $\mathrm{CD}^{+}$or $\mathrm{CD}^{+} \mathrm{T}$ cells within the spinal cords of mice treated with either FTY720 or vehicle alone (Figure 7, A and B). Moreover, infiltration of virus-specific $\mathrm{CD} 4^{+}$and $\mathrm{CD}^{+}{ }^{-} \mathrm{T}$ cells was not affected after FTY720 treatment (Figure 7, A and B).

Transplantation of GFP-NPCs into JHMV-infected mice did not affect infiltration of total $\mathrm{CD} 4^{+}$and $\mathrm{CD} 8^{+} \mathrm{T}$ cells nor virus-specific T cells into the spinal cord (Figure 7, C and D), and this is consistent with our previously published studies. ${ }^{46}$ Similarly, administration of FTY720 to infected mice transplanted with GFP-NPCs did not prevent total T-cell or virusspecific T-cell entry into the CNS (Figure 7, C and D). In addition, FTY720 did not affect T-cell infiltration into the brains of mice infected with JHMV alone or transplanted with GFP-NPCs (data not shown). We confirmed the biological activity of FTY720 during chronic disease by examining levels of circulating $\mathrm{T}$ cells within the blood. FTY720 significantly $(P<0.05)$ diminished the frequency of both $\mathrm{CD}^{+}$(Figure 8A) and $\mathrm{CD}^{+}$(Figure 8C) T cells within the blood compared with control mice. In addition, by using
S1P1 eGFP knock-in mice, we determined that surface expression of S1P1, measured by eGFP expression, was also decreased $(P<0.05)$ on circulating $\mathrm{CD}^{+}$(Figure $8 \mathrm{~B}$ ) and $\mathrm{CD}^{+} \mathrm{T}$ cells (Figure 8D) in FTY720-treated mice when compared with control animals. Therefore, FTY720 treatment of JHMV-infected mice results in diminished levels of circulating lymphocytes that correlates with decreased S1P1 expression, and this is consistent with our earlier findings. ${ }^{41}$ These results indicate that FTY720 does not affect T-cell migration into the CNS during chronic disease in animals, regardless of whether transplanted with GFP-NPCs or vehicle alone.

\section{Discussion}

The use of stem cells for treatment of human demyelinating diseases, such as MS, to induce tissue repair offers an attractive therapy for promoting remyelination and potentially sustained clinical recovery. ${ }^{11,42,47-50}$ After spinal cord engraftment of mouse NPCs into JHMV-infected mice, NPCs preferentially migrate to sites of demyelination by responding to the chemokine CXCL12 via expression of the receptor CXCR $4 .{ }^{9}$ However, it is likely that other signaling cues are present within this inflammatory demyelinating environment that influence NPC migration. The S1P/S1P1 axis has been shown to be involved in NPC migration to sites of damage in a model of spinal cord injury highlighting the importance of S1P receptors in mediating positional migration of NPCs. ${ }^{28}$ Treatment of mice with FTY720 

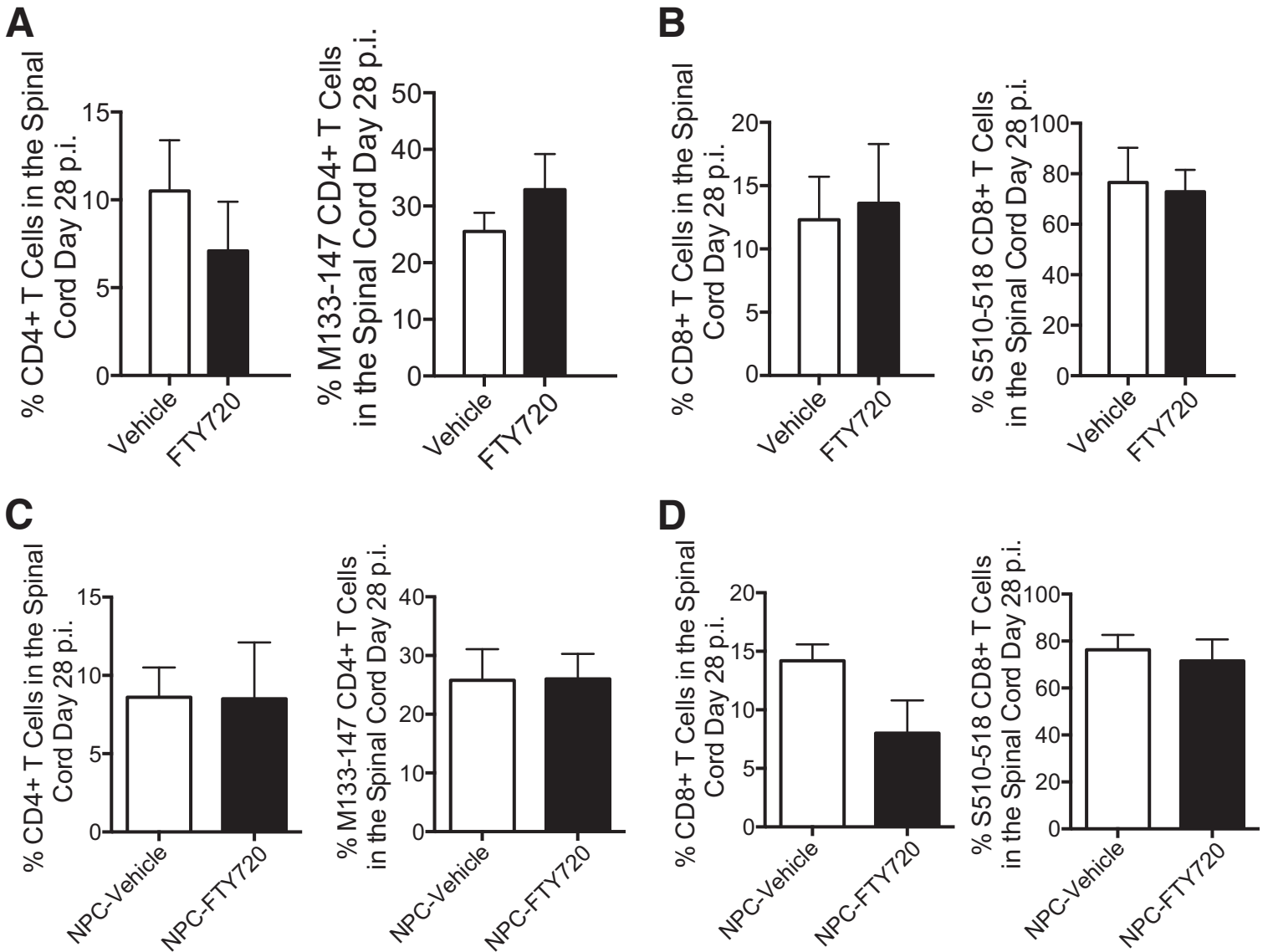

Figure 7 Treatment with FTY720 does not affect neuroinflammation in JHMV infected mice. The effect of FTY720 treatment on T-cell infiltration into the spinal cord after either JHMV infection alone or GFP-NPCs transplantation was examined. Spinal cords were removed at day 28 postinfection [p.i.; day 14 posttransplant (p.t.) of GFP-NPCs], and the frequency of total T-cell subsets and virus-specific T cells was determined. There is no difference in frequencies of $\mathrm{CD}^{+}(\mathbf{A})$ or $\mathrm{CD}^{+}$(B) T cells and virus-specific $\mathrm{CD}^{+}(\mathbf{A})$ or $\mathrm{CD8}^{+}(\mathbf{B})$ T cells in JHMV-infected mice treated with either vehicle control or FTY720. FTY720 does not reduce overall frequencies of infiltrating $\mathrm{CD}^{+}(\mathbf{C})$ or $\mathrm{CD}^{+}(\mathbf{D}) \mathrm{T}$ cells compared with vehicle-treated control mice nor are there differences in the frequencies of virus-specific $\mathrm{CD}^{+}(\mathbf{C})$ and $\mathrm{CD}^{+}$(D) T cells following spinal cord transplantation of GFP-NPCs. Data represent means $\pm \mathrm{SEM}(\mathbf{A}-\mathbf{D}) . n=4$ mice or more per group (A-D).

augments CXCR4 signaling and potentiates migration of hematopoietic stem cells. ${ }^{45}$ Moreover, FTY720 readily penetrates the CNS, ${ }^{19,24,33,51,52}$ arguing that it can modulate the biology of transplanted NPCs by binding to S1P receptors. Indeed, Gonzalez-Cabrera et $\mathrm{al}^{53}$ have shown that chronic FTY720 degrades and down modulates the receptor in the CNS. FTY720 has a 17:1 brain/plasma ratio and is accumulated in the brain, providing long-term steady-state levels that drive complete receptor occupancy and degradation. Therefore, we investigated the effects of FTY720 treatment in conjunction with NPC therapy in a viral model of MS.

Herein, we show that FTY720 treatment of JHMVinfected mice transplanted with GFP-NPCs results in enhanced migration of transplanted cells when compared with transplanted animals treated with vehicle control (Figure 3, A and C). FTY720 treatment did not alter positional migration of transplanted NPCs because these cells efficiently congregated within areas of demyelination (Figure 3, A and B). The in vivo migration data support our in vitro experimental results showing that FTY720 treatment of cultured NPCs increases migration after exposure to recombinant mouse CXCL12, and this was independent of elevated surface expression of CXCR4 on NPCs (Figure 4, A and B). These findings argue that a mechanism underlying enhanced NPC migration could involve an effect on CXCR4 function and/or the downstream signaling cascade, such as calcium mobilization or cytoskeleton rearrangement.

Previous studies have shown that FTY720 activates the phosphorylation of CXCR4 through S1P3 activation, followed by downstream cascade activation of Src kinase and Janus-activating kinase 2 in progenitor cells, ${ }^{54}$ and affects CXCR4-mediated migration in hematopoietic stem cells after exposure to CXCL12. ${ }^{45}$

Future work focusing on defining the specific S1P receptor(s) involved in elevated CXCR4 function will be critical to better understand the molecular mechanisms governing how receptor agonists/antagonists influence NPC migration mediated by CXCR4.

Our findings also indicated increased numbers of GFPNPCs within demyelinated white matter tracts of GFP-NPCs 

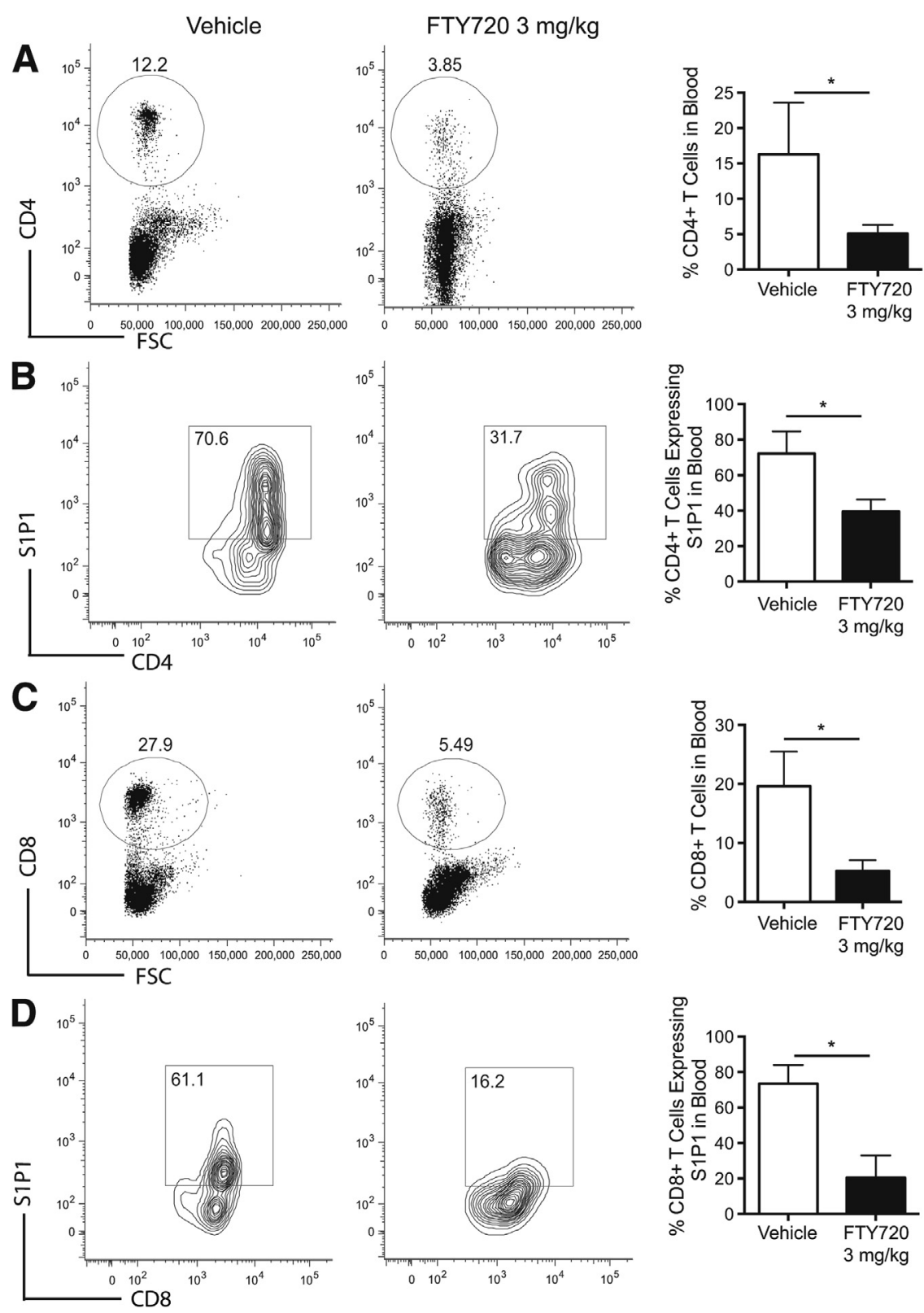

Figure 8 FTY720 induces lymphopenia and down-regulates sphingosine-1-phosphate receptor 1 (S1P1) on T cells. Frequencies of $\mathrm{CD}^{+}$and $\mathrm{CD}^{+}$ $T$ cells in the blood day 7 posttransplant with GFPNPCs into JHMV-infected S1P1 eGFP mice treated daily with FTY720 or control starting at day 13 postinfection. FTY720 significantly diminishes the frequency of both $\mathrm{CD}^{+}(\mathrm{A})$ and $\mathrm{CD}^{+}{ }^{+}(\mathrm{C}) \mathrm{T}$ cells and S1P1 expression measured by GFP expression on $\mathrm{CD}^{+}(\mathbf{B})$ and $\mathrm{CD}^{+}$(D) T cells. Data are presented as means $\pm \operatorname{SEM}(\mathbf{A}-\mathbf{D}) . n=2$ or more experiments with a minimum $n=4$ per group (A-D). ${ }^{*} P<0.05$. FSC, forward scatter. in JHMV-infected mice treated with FTY720 when compared with transplanted mice treated with vehicle control, suggesting proliferation is increased in vivo. Collectively, these results argue that FTY720 treatment increased NPC migration and proliferation following engraftment.

We have recently shown that FTY720 treatment of JHMV-infected mice during acute disease results in increased mortality that is associated with impaired migration of virus-specific T cells into the CNS and elevated viral titers within the $\mathrm{CNS}^{41}$ Dampened neuroinflammation correlated with increased cellularity of draining cervical lymph nodes, consistent with previous reports indicating that S1P antagonism impairs lymphocyte egress from lymphatic tissue. ${ }^{19,20,51,52}$ More important, administration of FTY720 to JHMV-infected mice during acute disease was associated with diminished severity of demyelination. These findings highlight an important role for S1P signaling in host defense during acute viral-induced neurological disease, most likely by enhancing $\mathrm{T}$ cells to efficiently migrate from lymphatic tissue into the CNS. In marked contrast, the present study indicates that when FTY720 treatment is initiated at day 13 p.i. with JHMV, there is no effect on T-cell accumulation within the CNS, and the severity of demyelination is not affected. We believe these differences in outcomes with regard to neuroinflammation reflect the stage of disease at which point FTY720 is administered. As indicated above, FTY720 treatment during acute disease limited egress of virus-specific $\mathrm{T}$ cells from draining cervical lymph nodes, thereby reducing the severity of neuroinflammation and demyelination. By day 13 p.i., surviving 
mice have reduced viral titers below the level of detection as a result of infiltration of virus-specific T cells into the CNS that can effectively control viral replication. Correspondingly, treatment with FTY720 would have limited-to-no effect on disease progression at this stage of disease because the bulk of virus-specific lymphocytes have already expanded and exited the draining cervical lymph nodes and subsequently infiltrated the CNS. In addition, these data also indicate that $\mathrm{T}$ cells do not rely on S1P signaling for T-cell migration to the CNS during chronic disease but rather use other inflammatory signaling cues (eg, chemokines) to gain access to the CNS of JHMV-infected mice. ${ }^{2,55}$

Although FTY720 treatment of cultured NPCs resulted in activation, increased proliferation, and enhanced migration in response to CXCL12, there was no effect on lineage fate commitment because similar frequencies of oligodendroglia, astrocytes, and neurons were observed compared with NPCs treated with control vehicle. Similar frequencies of GFP-positive oligodendroglia expressing GST- $\pi$ were detected within spinal cords of GFP-NPC-transplanted mice treated with either FTY720 or vehicle control. Although there were increased numbers of GFP-NPCs within areas of demyelination in FTY720-treated mice, we did not observe any discernable increase in remyelination. Whether this is because of functional deficits in these cells is currently unknown and is the focus of ongoing studies.

We have previously shown that engrafted NPCs can remyelinate demyelinated axons, ${ }^{11}$ and these findings would argue that FTY720 does not increase the remyelination potential of engrafted NPCs in our model of viralinduced demyelination. This is similar to previous studies that determined that FTY720 does not induce remyelination in either the cuprizone or lysophosphatidyl choline models of demyelination. ${ }^{56}$ However, Miron et al ${ }^{57}$ have demonstrated that FTY720 treatment resulted in increased remyelination in organotypic cerebral slices where demyelination was induced by lysolecithin. These findings support other studies demonstrating FTY720 treatment in augmenting neurogenesis and repair in models of CNS injury, possibly by activating endogenous NPCs and/or oligodendrocyte progenitor cells. ${ }^{58-62} \mathrm{We}$ are currently examining whether FTY720 activates endogenous progenitor cells within the CNS of JHMV-infected mice. The conflicting reports on the effects of FTY720 on remyelination highlight differences in model systems used, emphasizing the potential importance of targeting specific receptors for promoting OPC maturation and myelin synthesis. For example, by using a lysophosphatidyl choline-induced model of demyelination, administration of S1P5 agonist has been reported to have a greater effect on remyelination compared with S1P1 agonists. ${ }^{63}$ FTY720 treatment of MS patients with the relapsingremitting form of disease reduced the risk of disability progression; yet, it is not clear if this is because of an increase in remyelination. ${ }^{64}$ The fact that we did not observe any increase in remyelination in JHMV-infected mice treated with FTY720 alone would argue additional studies in preclinical models of MS with more selective S1P receptor agonists or antagonists to better understand the effects on both endogenous glial cells and transplanted NPCs with regard to promoting remyelination.

\section{Acknowledgments}

We thank Edna Hingco and Colleen Worne for excellent technical assistance.

\section{References}

1. Bergmann CC, Lane TE, Stohlman SA: Coronavirus infection of the central nervous system: host-virus stand-off. Nat Rev Microbiol 2006, 4:121-132

2. Glass WG, Hickey MJ, Hardison JL, Liu MT, Manning JE, Lane TE Antibody targeting of the $\mathrm{CC}$ chemokine ligand 5 results in diminished leukocyte infiltration into the central nervous system and reduced neurologic disease in a viral model of multiple sclerosis. J Immunol 2004, 172:4018-4025

3. Hosking MP, Lane TE: The biology of persistent infection: inflammation and demyelination following murine coronavirus infection of the central nervous system. Curr Immunol Rev 2009, 5:267-276

4. Lane TE, Hosking MP: The pathogenesis of murine coronavirus infection of the central nervous system. Crit Rev Immunol 2010, 30:119-130

5. Marten NW, Stohlman SA, Bergmann CC: MHV infection of the CNS: mechanisms of immune-mediated control. Viral Immunol 2001, $14: 1-18$

6. Perlman SR, Lane TE, Buchmeier MJ: Coronaviruses: hepatitis, peritonitis, and central nervous system disease. Edited by Cunningham MW, Fujinami RS. Effects of Microbes on the Immune System. Philadelphia, Lippincott Williams \& Wilkins, 1999, pp $331-348$

7. Stohlman SA, Hinton DR: Viral induced demyelination. Brain Pathol 2001, 11:92-106

8. Totoiu MO, Nistor GI, Lane TE, Keirstead HS: Remyelination, axonal sparing, and locomotor recovery following transplantation of glial-committed progenitor cells into the MHV model of multiple sclerosis. Exp Neurol 2004, 187:254-265

9. Carbajal KS, Schaumburg C, Strieter R, Kane J, Lane TE: Migration of engrafted neural stem cells is mediated by CXCL12 signaling through CXCR4 in a viral model of multiple sclerosis. Proc Natl Acad Sci U S A 2010, 107:11068-11073

10. Whitman LM, Blanc CA, Schaumburg CS, Rowitch DH, Lane TE: Olig1 function is required for remyelination potential of transplanted neural progenitor cells in a model of viral-induced demyelination. Exp Neurol 2012, 235:380-387

11. Greenberg ML, Weinger JG, Matheu MP, Carbajal KS, Parker I, Macklin WB, Lane TE, Cahalan MD: Two-photon imaging of remyelination of spinal cord axons by engrafted neural precursor cells in a viral model of multiple sclerosis. Proc Natl Acad Sci U S A 2014, 111:E2349-E2355

12. Einstein O, Friedman-Levi Y, Grigoriadis N, Ben-Hur T: Transplanted neural precursors enhance host brain-derived myelin regeneration. J Neurosci 2009, 29:15694-15702

13. Einstein O, Grigoriadis N, Mizrachi-Kol R, Reinhartz E Polyzoidou E, Lavon I, Milonas I, Karussis D, Abramsky O, BenHur T: Transplanted neural precursor cells reduce brain inflammation to attenuate chronic experimental autoimmune encephalomyelitis. Exp Neurol 2006, 198:275-284

14. Pluchino S, Gritti A, Blezer E, Amadio S, Brambilla E, Borsellino G, Cossetti C, Del Carro U, Comi G, 't Hart B, Vescovi A, Martino G: 
Human neural stem cells ameliorate autoimmune encephalomyelitis in non-human primates. Ann Neurol 2009, 66:343-354

15. Harada J, Foley M, Moskowitz MA, Waeber C: Sphingosine-1phosphate induces proliferation and morphological changes of neural progenitor cells. J Neurochem 2004, 88:1026-1039

16. Pebay A, Toutant M, Premont J, Calvo CF, Venance L, Cordier J, Glowinski J, Tence M: Sphingosine-1-phosphate induces proliferation of astrocytes: regulation by intracellular signalling cascades. Eur J Neurosci 2001, 13:2067-2076

17. Kimura T, Watanabe T, Sato K, Kon J, Tomura H, Tamama K, Kuwabara A, Kanda T, Kobayashi I, Ohta H, Ui M, Okajima F: Sphingosine 1-phosphate stimulates proliferation and migration of human endothelial cells possibly through the lipid receptors, Edg-1 and Edg-3. Biochem J 2000, 348(Pt 1):71-76

18. Kong Y, Wang H, Lin T, Wang S: Sphingosine-1-phosphate/S1P receptors signaling modulates cell migration in human bone marrowderived mesenchymal stem cells. Mediators Inflamm 2014, 2014: 565369

19. Brinkmann V, Billich A, Baumruker T, Heining P, Schmouder R, Francis G, Aradhye S, Burtin P: Fingolimod (FTY720): discovery and development of an oral drug to treat multiple sclerosis. Nat Rev Drug Discov 2010, 9:883-897

20. Matloubian M, Lo CG, Cinamon G, Lesneski MJ, Xu Y, Brinkmann V, Allende ML, Proia RL, Cyster JG: Lymphocyte egress from thymus and peripheral lymphoid organs is dependent on S1P receptor 1. Nature 2004, 427:355-360

21. Pinschewer DD, Brinkmann V, Merkler D: Impact of sphingosine 1-phosphate modulation on immune outcomes. Neurology 2011, 76: S15-S19

22. Cohen JA, Chun J: Mechanisms of fingolimod's efficacy and adverse effects in multiple sclerosis. Ann Neurol 2011, 69:759-777

23. Aktas O, Kury P, Kieseier B, Hartung HP: Fingolimod is a potential novel therapy for multiple sclerosis. Nat Rev Neurol 2010, 6: $373-382$

24. Choi JW, Gardell SE, Herr DR, Rivera R, Lee CW, Noguchi K, Teo ST, Yung YC, Lu M, Kennedy G, Chun J: FTY720 (fingolimod) efficacy in an animal model of multiple sclerosis requires astrocyte sphingosine 1-phosphate receptor 1 (S1P1) modulation. Proc Natl Acad Sci U S A 2011, 108:751-756

25. Durafourt BA, Lambert C, Johnson TA, Blain M, Bar-Or A, Antel JP: Differential responses of human microglia and blood-derived myeloid cells to FTY720. J Neuroimmunol 2011, 230:10-16

26. Miron VE, Hall JA, Kennedy TE, Soliven B, Antel JP: Cyclical and dose-dependent responses of adult human mature oligodendrocytes to fingolimod. Am J Pathol 2008, 173:1143-1152

27. Spohr TC, Dezonne RS, Nones J, Dos Santos Souza C, EinickerLamas M, Gomes FC, Rehen SK: Sphingosine 1-phosphate-primed astrocytes enhance differentiation of neuronal progenitor cells. J Neurosci Res 2012, 90:1892-1902

28. Kimura A, Ohmori T, Ohkawa R, Madoiwa S, Mimuro J, Murakami T, Kobayashi E, Hoshino Y, Yatomi Y, Sakata Y: Essential roles of sphingosine 1-phosphate/S1P1 receptor axis in the migration of neural stem cells toward a site of spinal cord injury. Stem Cells 2007, 25:115-124

29. Ingwersen J, Aktas O, Kuery P, Kieseier B, Boyko A, Hartung HP: Fingolimod in multiple sclerosis: mechanisms of action and clinical efficacy. Clin Immunol 2012, 142:15-24

30. Mehling M, Johnson TA, Antel J, Kappos L, Bar-Or A: Clinical immunology of the sphingosine 1-phosphate receptor modulator fingolimod (FTY720) in multiple sclerosis. Neurology 2011, 76: S20-S27

31. O'Connor P, Comi G, Montalban X, Antel J, Radue EW, de Vera A, Pohlmann H, Kappos L, Group FDS: Oral fingolimod (FTY720) in multiple sclerosis: two-year results of a phase II extension study. Neurology 2009, 72:73-79

32. Willis MA, Cohen JA: Fingolimod therapy for multiple sclerosis. Semin Neurol 2013, 33:37-44
33. Groves A, Kihara Y, Chun J: Fingolimod: direct CNS effects of sphingosine 1-phosphate (S1P) receptor modulation and implications in multiple sclerosis therapy. J Neurol Sci 2013, 328:9-18

34. Cahalan SM, Gonzalez-Cabrera PJ, Sarkisyan G, Nguyen N, Schaeffer MT, Huang L, Yeager A, Clemons B, Scott F, Rosen H: Actions of a picomolar short-acting S1P(1) agonist in S1P(1)-eGFP knock-in mice. Nat Chem Biol 2011, 7:254-256

35. Lane TE, Liu MT, Chen BP, Asensio VC, Samawi RM, Paoletti AD, Campbell IL, Kunkel SL, Fox HS, Buchmeier MJ: A central role for CD4(+) T cells and RANTES in virus-induced central nervous system inflammation and demyelination. J Virol 2000, 74:1415-1424

36. Ben-Hur T, Rogister B, Murray K, Rougon G, Dubois-Dalcq M: Growth and fate of PSA-NCAM+ precursors of the postnatal brain. J Neurosci 1998, 18:5777-5788

37. Whitman L, Zhou H, Perlman S, Lane TE: IFN-gamma-mediated suppression of coronavirus replication in glial-committed progenitor cells. Virology 2009, 384:209-215

38. Nistor GI, Totoiu MO, Haque N, Carpenter MK, Keirstead HS: Human embryonic stem cells differentiate into oligodendrocytes in high purity and myelinate after spinal cord transplantation. Glia 2005, 49:385-396

39. Carbajal KS, Weinger JG, Whitman LM, Schaumburg CS, Lane TE: Surgical transplantation of mouse neural stem cells into the spinal cords of mice infected with neurotropic mouse hepatitis virus. J Vis Exp 2011, (53):e2834

40. Keirstead HS, Nistor G, Bernal G, Totoiu M, Cloutier F, Sharp K, Steward O: Human embryonic stem cell-derived oligodendrocyte progenitor cell transplants remyelinate and restore locomotion after spinal cord injury. J Neurosci 2005, 25:4694-4705

41. Blanc CA, Rosen H, Lane TE: FTY720 (fingolimod) modulates the severity of viral-induced encephalomyelitis and demyelination. J Neuroinflammation 2014, 11:138

42. Chen L, Coleman R, Leang R, Tran H, Kopf A, Walsh CM, SearsKraxberger I, Steward O, Macklin WB, Loring JF, Lane TE: Human neural precursor cells promote neurologic recovery in a viral model of multiple sclerosis. Stem Cell Rep 2014, 2:825-837

43. Xin C, Ren S, Eberhardt W, Pfeilschifter J, Huwiler A: The immunomodulator FTY720 and its phosphorylated derivative activate the Smad signalling cascade and upregulate connective tissue growth factor and collagen type IV expression in renal mesangial cells. Br J Pharmacol 2006, 147:164-174

44. Osinde M, Mullershausen F, Dev KK: Phosphorylated FTY720 stimulates ERK phosphorylation in astrocytes via S1P receptors. Neuropharmacology 2007, 52:1210-1218

45. Kimura T, Boehmler AM, Seitz G, Kuci S, Wiesner T, Brinkmann V, Kanz L, Mohle R: The sphingosine 1-phosphate receptor agonist FTY720 supports CXCR4-dependent migration and bone marrow homing of human CD34+ progenitor cells. Blood 2004, 103: $4478-4486$

46. Hardison JL, Nistor G, Gonzalez R, Keirstead HS, Lane TE: Transplantation of glial-committed progenitor cells into a viral model of multiple sclerosis induces remyelination in the absence of an attenuated inflammatory response. Exp Neurol 2006, 197:420-429

47. Cristofanilli M, Harris VK, Zigelbaum A, Goossens AM, Lu A, Rosenthal H, Sadiq SA: Mesenchymal stem cells enhance the engraftment and myelinating ability of allogeneic oligodendrocyte progenitors in dysmyelinated mice. Stem Cells Dev 2011, 20: $2065-2076$

48. Gupta N, Henry RG, Strober J, Kang SM, Lim DA, Bucci M, Caverzasi E, Gaetano L, Mandelli ML, Ryan T, Perry R, Farrell J, Jeremy RJ, Ulman M, Huhn SL, Barkovich AJ, Rowitch DH: Neural stem cell engraftment and myelination in the human brain. Sci Transl Med 2012, 4:155ra37

49. Harris VK, Faroqui R, Vyshkina T, Sadiq SA: Characterization of autologous mesenchymal stem cell-derived neural progenitors as a feasible source of stem cells for central nervous system applications in multiple sclerosis. Stem Cells Transl Med 2012, 1:536-547 
50. Harris VK, Yan QJ, Vyshkina T, Sahabi S, Liu X, Sadiq SA: Clinical and pathological effects of intrathecal injection of mesenchymal stem cell-derived neural progenitors in an experimental model of multiple sclerosis. J Neurol Sci 2012, 313:167-177

51. Chun J, Brinkmann V: A mechanistically novel, first oral therapy for multiple sclerosis: the development of fingolimod (FTY720, Gilenya). Discov Med 2011, 12:213-228

52. Chun J, Hartung HP: Mechanism of action of oral fingolimod (FTY720) in multiple sclerosis. Clin Neuropharmacol 2010, 33:91-101

53. Gonzalez-Cabrera PJ, Cahalan SM, Nguyen N, Sarkisyan G, Leaf NB, Cameron MD, Kago T, Rosen H: S1P(1) receptor modulation with cyclical recovery from lymphopenia ameliorates mouse model of multiple sclerosis. Mol Pharmacol 2012, 81:166-174

54. Walter DH, Rochwalsky U, Reinhold J, Seeger F, Aicher A, Urbich C, Spyridopoulos I, Chun J, Brinkmann V, Keul P, Levkau B, Zeiher AM, Dimmeler S, Haendeler J: Sphingosine-1-phosphate stimulates the functional capacity of progenitor cells by activation of the CXCR4-dependent signaling pathway via the S1P3 receptor. Arterioscler Thromb Vasc Biol 2007, 27:275-282

55. Liu MT, Keirstead HS, Lane TE: Neutralization of the chemokine CXCL10 reduces inflammatory cell invasion and demyelination and improves neurological function in a viral model of multiple sclerosis. J Immunol 2001, 167:4091-4097

56. Hu Y, Lee X, Ji B, Guckian K, Apicco D, Pepinsky RB, Miller RH, Mi S: Sphingosine 1-phosphate receptor modulator fingolimod (FTY720) does not promote remyelination in vivo. Mol Cell Neurosci 2011, 48:72-81
57. Miron VE, Ludwin SK, Darlington PJ, Jarjour AA, Soliven B, Kennedy TE, Antel JP: Fingolimod (FTY720) enhances remyelination following demyelination of organotypic cerebellar slices. Am J Pathol 2010, 176:2682-2694

58. Cui QL, Fang J, Kennedy TE, Almazan G, Antel JP: Role of p38MAPK in S1P receptor-mediated differentiation of human oligodendrocyte progenitors. Glia 2014, 62:1361-1375

59. McGiffert C, Contos JJ, Friedman B, Chun J: Embryonic brain expression analysis of lysophospholipid receptor genes suggests roles for $\mathrm{s} 1 \mathrm{p}(1)$ in neurogenesis and $\mathrm{s} 1 \mathrm{p}(1-3)$ in angiogenesis. FEBS Lett 2002, 531:103-108

60. Miron VE, Schubart A, Antel JP: Central nervous system-directed effects of FTY720 (fingolimod). J Neurol Sci 2008, 274:13-17

61. Rolland WB 2nd, Manaenko A, Lekic T, Hasegawa Y, Ostrowski R, Tang J, Zhang JH: FTY720 is neuroprotective and improves functional outcomes after intracerebral hemorrhage in mice. Acta Neurochir Suppl 2011, 111:213-217

62. Miron VE, Jung CG, Kim HJ, Kennedy TE, Soliven B, Antel JP: FTY720 modulates human oligodendrocyte progenitor process extension and survival. Ann Neurol 2008, 63:61-71

63. Jackson SJ, Giovannoni G, Baker D: Fingolimod modulates microglial activation to augment markers of remyelination. J Neuroinflammation 2011, 8:76

64. Kappos L, Radue EW, O'Connor P, Polman C, Hohlfeld R, Calabresi P, Selmaj K, Agoropoulou C, Leyk M, Zhang-Auberson L, Burtin P, Group FS: A placebo-controlled trial of oral fingolimod in relapsing multiple sclerosis. N Engl J Med 2010, 362:387-401 